\title{
Stem Cell Based Tissue-Engineered Grafts for Articular Cartilage Defects- a Mini Review
}

\author{
Amit Kumar Singh and Krishna Pramanik* \\ Center of Excellent in Tissue Engineering, Department of Biotechnology \& Medical Engineering, National Institute of Technology, India
}

Received: May 31, 2018; Published: June 13, 2018

*Corresponding author: Krishna Pramanik, Center of Excellent in Tissue Engineering, Department of Biotechnology \& Medical Engineering, National Institute of Technology, Rourkela, India

\section{Mini Review}

Millions of patient report hospital with joint and articular cartilage injuries that are usually occur in knee, wrist, and ankle joints. Among these, knee injury is the most critical and common one. People also suffer from knee arthritis which is caused by progressive cartilage tissue loss due to wear and tear [1]. Among the different joints affected by osteoarthritis, knee arthritis is the most critical that resists patients from doing everyday activities [2]. In osteoarthritis, the cartilage in the knee joint gradually wears away which further exposes the bony ends thereby affecting subchondral bone site of the knee and ultimately produces painful bone spurs [3]. Articular cartilage defects are difficult to heal due to their avascular nature and the repair process is only transient and imperfect, and tissue degeneration eventually occurs leading to the progressive deposition of subchondral bone [4,5]. Osteochondral lesion involving both articular cartilage surface and underlying subchondral bone, essentially forms fibrocartilage and loose its ability to protect subchondral bone degeneration [6]. All these events lead to severe pain, joint deformity, and retardation of joint mobility.

More than 51 million peoples had been reported to visit hospitals with some form of arthritis in USA only $[7,8]$. The currently used mosaicplasty, autologous chondrocytes transplantation and marrow stimulation techniques for the treatment of damaged cartilage and subchondral bone tissue often offer unsatisfactory outcome eventually lead to the continuing of pain $[9,10]$. The recently emerged tissue engineering technique has brought a new hope to the patients providing a suitable strategy for the regeneration and repairing of the damaged tissues through developing biologically functionalized scaffolds derived from biomaterials with appropriate properties mimicking body tissue [11-13]. However, it is quite obvious that TE, being new have numerous challenges starting with its development to actual application in human health care. The success of TE depends on various factors that often relate to patient's defect site, properties of scaffold acts as a platform for cell career, cell types for neo tissue generation and level of interaction between scaffold and native body tissue [12,13]. The tissue-engineered scaffold developed from biodegradable and biocompatible polymers combined with bioactive ceramics are proven to be promising, however, the success of these techniques largely determined by the fabrication methods, cell source and signaling factors [14-17].

Though electrospinning has been evolved as the suitable fabrication technique [18] and being widely used so far, rapid prototyping technique, bioprinting in particular, is considered as the most appropriate which needs further development for its commercial availability with affordable cost [19]. Another important factor for the success of TE is to develop cartilagebone interfaces that should be intact after implantation. Novel strategies suggest the fabrication of scaffolds with distinct layers of different biomaterials $[20,21]$. Stem cells, specifically mesenchymal stem cells possessing excellent chondrogenic and osteogenic differentiation capability are attractive cell source. Suitable cell signaling factors such as specific growth factors, mechanical and electrical stimulation and gas exchange are important to trigger and regulate cell differentiation and to improve mechanical property of the cartilage tissue after implantation [22].

The repair of osteochondral tissue defect involves much critical challenges as it is often associated with the risk of changes in cell phenotype and structural de-organization of the native tissue by the regeneration of neo-cartilage tissue [23-24]. It is, therefore, important to assure the ability of the scaffolds towards tissue integration through in vivo study using animal model with variation in defect thickness, angiogenesis, inflammatory effect and long-term stability to translate in-vitro data into clinically relevant approaches. To simulate in vitro tissue formation at optimal level, a suitable bioreactor system and its scale up are important. In this context, perfusion bioreactor is efficient that provides dynamic culture system resulting in the homogeneous cell distribution 
throughout the scaffold and offers better nutrient exchange [2527]. The preservation of the tissue engineered grafts on long-term perspective is important for commercialization of these products [28].

\section{References}

1. Makris EA, Hadidi P, Athanasiou KA (2011) The knee meniscus: structure-function, pathophysiology, current repair techniques, and prospects for regeneration. Biomaterials 32(30): 7411-7431.

2. Romanelli, D, John Uribe MD, Diane SWatanabe ATC, Bert R Mandelbaum MD (2008) Articular cartilage injuries. Rosemont: American Orthopaedics Society for Sports Medicine.

3. Coventry, Mark B (1973) Osteotomy about the knee for degenerative and rheumatoid arthritis. J Bone Joint Surg Am 55(1): 23-48.

4. Responte DJ, Natoli RM, Athanasiou KA (2007) Collagens of articular cartilage: structure, function, and importance in tissue engineering. Crit Rev Biomed Eng 35(5): 363-411.

5. Ateshian GA, Warden WH, Kim JJ, Grelsamer RP, Mow VC (1997) Finite deformation biphasic material properties of bovine articular cartilage from confined compression experiments. J Biomech 30(11-12): 11571164

6. Cartilage org Zürich (2009) International Cartilage Repair Society.

7. Lawrence Reva C, David T Felson MD, Charles G. Helmick MD, Lesley M Arnold MD, Hyon Choi MD, et al. (2008) Estimates of the prevalence of arthritis and other rheumatic conditions in the United States: Part II. Arthritis \& Rheumatism 58(1): 26-35.

8. National Health Portal of India.

9. Vijayan S, G Bentley, TWR Briggs, JA Skinner, RWJ Carrington et al. (2010) Cartilage repair: a review of Stanmore experience in the treatment of osteochondral defects in the knee with various surgical techniques. Indian journal of orthopaedics 44(3): 238-245.

10. Dunkin, Brad S, Christian Lattermann (2013) New and emerging techniques in cartilage repair: Matrix-induced autologous chondrocyte implantation. Operative techniques in sports medicine 21(2): 100-107.

11. Lee, Soo-Hong, Heungsoo Shin (2007) Matrices and scaffolds for delivery of bioactive molecules in bone and cartilage tissue engineering Advanced drug delivery reviews 59(4-5): 339-359.

12. Visser Jetze (2015) Biofabrication of implants for articular joint repair: Cartilage regeneration in reinforced gelatin-based hydrogels pp. 1-295.

13. Matsiko Amos, Tanya J Levingstone, Fergal J O Brien (2013) Advanced strategies for articular cartilage defect repair. Materials 6(2): 637-668.

14. Panda A, Bissoyi A, Pramanik K, Biswas A (2015) Development of novel electrospun scaffold from P. ricini and A. mylitta silk fibroin blend with improved surface and biological properties. Mat. Science \& Engg. C 48: 521-532.

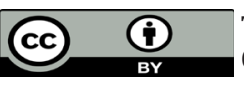

This work is licensed under Creative Commons Attribution 4.0 License

Submission Link: https://biomedres.us/submit-manuscript.php
15. Varshini V, Pramanik K, Biswas A (2016) Optimization and evaluation of silk fibroin-chitosan freeze-dried porous scaffolds for cartilage tissue engg application. J Biomaterials Science, Polymer 27(7): 657-674.

16. Singh BN, Panda NN, Mund R, Pramanik K (2016) Carboxymethyl cellulose enables silk fibroin nanofibrous scaffold with enhanced biomimetic potential for bone tissue engg. application. Carbohydrate Polymers 151: 335-347.

17. Nooeaid Patcharakamon, Salih V, Beier JP, Boccaccini AR (2012) Osteochondral tissue engineering: scaffolds, stem cells and applications. Journal of cellular and molecular medicine16(10): 2247-2270.

18. Dvir Tal, Timko BP, Kohane DS, Langer R (2011) Nanotechnological strategies for engineering complex tissues. Nature nanotechnology 6(1): 13-22.

19. Rothwell Roy (1994) Towards the fifth-generation innovation process. International marketing review 11(1): 7-31.

20. Nooeaid Patcharakamon, Salih V, Beier JP, Boccaccini AR (2012) Osteochondral tissue engineering: scaffolds, stem cells and applications. Journal of cellular and molecular medicine 16(10): 2247-2270.

21. Harley Brendan A, Lynn AK, Wissner-Gross Z, Bonfield W, Yannas, et al. (2010) Design of a multiphase osteochondral scaffold III: Fabrication of layered scaffolds with continuous interfaces. J Biomedical Mat. Research Part A 92(3): 1078-1093.

22. Vinatier Claire, Mrugala D, Jorgensen C, Guicheux J, Noël D (2009) Cartilage engineering: a crucial combination of cells, biomaterials and biofactors. Trends in biotechnology 27(5): 307-314.

23. Johnstone Brian, Alini M, Cucchiarini M, Dodge GR, Eglin D, et al. (2013) Tissue engineering for articular cartilage repair-the state of the art. Eur Cell Mater 25: 248-267.

24. Nooeaid Patcharakamon, Salih V, Beier JP, Boccaccini AR (2012) Osteochondral tissue engineering: scaffolds, stem cells and applications. Journal of cellular and molecular medicine 16(10): 2247-2270.

25. Glowacki J, S Mizuno, J S Greenberger (1998) Perfusion enhances functions of bone marrow stromal cells in three-dimensional culture. Cell Transplant 7(3): 319-326.

26. Agrawal P, Pramanik K, Amit Biswas, Ranjan Ku Patra (2018) In vitro cartilage construct generation from silk fibroin- chitosan porous scaffold and human mesenchymal stem cells in dynamic culture conditions. J. of Biomedical Materials Research: Part A 106(2): 397-407.

27. Agarwal P, Pramanik K, Vishwanath V, Amit Biswas, Bissoyi A, et al. (2018) Enhanced chondrogenesis of mesenchymal stem cells over silk fibroin/chitosan - chondroitin sulphate three dimensional scaffold in dynamic culture condition . J. of Biomedical Materials Research: Part BApplied Biomaterials.

28. Bissoyi A, Pramanik K, Panda NN, Sarangi SK (2014) Cryopreservation of hMSCs seeded silk nanofibers based tissue engineered constructs Cryobiology 68(3): 332-342.

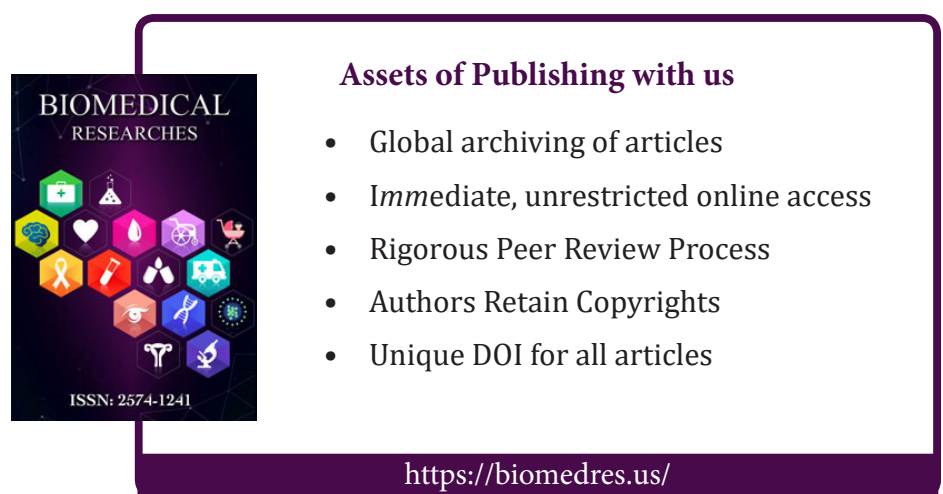

